\title{
Applying Behavioral Insights to Improve Tax Compliance in Papua New Guinea
}

\section{Appendix: Pre-Analysis Plan}

\author{
Christopher Hoy \\ ANU Crawford School of Public Policy \\ Mathias Sinning \\ ANU Crawford School of Public Policy, PKU NSD/CCER, RWI and IZA
}

10 April 2019

\begin{abstract}
The aim of this trial is to test the effectiveness of messages to improve tax compliance in Papua New Guinea (PNG) in a setting where the threat of punishment from non-compliance lacks credibility. We will test two types of interventions in collaboration with the Internal Revenue Commission (IRC). Firstly, we will test the effects of SMS messages on taxpayer behavior. Two alternative messages will be sent to taxpayers to remind them to lodge their tax return (Treatment Group 1A) and to inform them that their taxes are being used to fund education, healthcare and infrastructure (Treatment Group 2A). A control group will not receive any communication from the IRC over the duration of the trial (Control Group A). Taxpayers are being assigned randomly to the two treatment groups and to the control group. Secondly, we will test the effect of a flyer that is designed to encourage taxpayers to pay their taxes by informing taxpayers that their taxes are being used to fund education and healthcare. Taxpayers that receive a letter from the IRC for notification purposes will be randomly assigned to a group that will receive a letter and a flyer (Treatment Group 1B) and a group that will only receive a letter but no flyer (Control Group B). This document is the original ex ante analysis plan for the trial.
\end{abstract}

JEL-Classification: C93, H24, H25, H26

Keywords: Tax Compliance, Natural Field Experiment, Behavioral Insights

All correspondence to Mathias Sinning, Tax and Transfer Policy Institute, Crawford School of Public Policy, JG Crawford Building \#132, Lennox Crossing, The Australian National University, Canberra ACT 2601, T: +61 26125 1284, E: mathias.sinning@anu.edu.au. 


\section{Overview}

\section{Timing of events}

The IRC has begun to send out SMS messages in March 2019 (through Digicel). The flyers will be sent out over the coming months. De-identified data will be made available by the IRC after the registration of the trial in the AEA RCT Registry.

\section{Interventions}

Two types of interventions will be studied:

1. SMS messages: a message that reminds taxpayer to lodge their tax return (Treatment $1 \mathrm{~A}$ ) and a message that informs taxpayers that their taxes will be used to fund education, healthcare and infrastructure (Treatment 2A). The messages are attached in Appendix A at the end of this document.

2. Flyer: a flyer that informs taxpayers that their taxes will be used to fund education and healthcare (Treatment 1B). A draft flyer is attached in Appendix A.

Treatments will be compared to randomly assigned control groups consisting of individuals who are not being contacted by the IRC over the duration of the trial. The treatment effect of each intervention will be measured by comparing average outcomes between treatment and control groups. No interaction between treatments will be tested.

\section{Randomization}

For the SMS trial, de-identified baseline data were provided by the IRC for the population of taxpayers registered to pay Salary and Wages Tax (SWT) and Goods and Services Tax (GST). The baseline data were used for stratified randomization. A list of variables that was used to stratify is provided in Appendix B. Randomization was done in Stata using the command randtreat (version 1.4, 5 April 2017) using a random seed. A total of 23,489 observations was assigned randomly to Treatment Group 1A (7,797 
observations), Treatment Group 2A (7,818 observations) and Control Group A (7,874 observations).

For the flyer trial, the population of taxpayers who missed the deadline for lodging taxes in the previous month is randomly divided based upon whether the last digit of their Tax Identification Number (TIN) is an odd or even number. Within this population, taxpayers with a TIN that is an odd number are assigned to receive a flyer in addition to the letter.

\section{Regression specification}

We aim to estimate separate regression models to compare the members of one of the two treatment groups $t=1,2$, to the control group. Each of the two analysis samples includes $n_{t}$ members of treatment group $t=1,2$, and $n_{0}$ members of the control group. Given this setup, the general strategy for studying the effect of treatment $t$ on an outcome measure of interest will be to estimate the following model:

$$
Y_{i}^{t}=\beta_{0}^{t}+\beta_{1}^{t} T_{i}^{t}+\varepsilon_{i}^{t}, \quad i=\underbrace{1,2, \ldots, n_{0}}_{\text {control group }}, \underbrace{n_{0}+1, n_{0}+2, \ldots, n_{0}+n_{t}}_{\text {treatment group } t}, \quad t=1,2
$$

where $Y_{i}^{t}$ is a given outcome of taxpayer $i . T_{i}^{t}$ is the treatment indicator for the comparison of treatment group $t$ to the control group and $\varepsilon_{i}^{t}$ is the model error term. The parameter of interest is $\beta_{1}^{t}$, the (unconditional) average treatment effect on the treated. Key outcome measures are variables capturing individual lodgment, reporting and payment behavior. Our main outcomes of interest are:

- Timing of SWT lodgement

- Number of times SWT was lodged

- Amount of SWT paid

- Total payment of SWT

- Number of employees reported by taxpayers 
- Timing of GST lodgement

- Number of GST was lodged

- Amount of GST paid

- Gross income reported by taxpayer

In addition to equation (1), we will also estimate separate models for each treatment/control comparison including a set of control variables. Given the notation above, these models may be summarized by the following equation:

$$
Y_{i}^{t}=\gamma_{0}^{t}+\gamma_{1}^{t} T_{i}^{t}+X_{i}^{t} \gamma_{2}^{t}+\eta_{i}^{t}, \quad i=1,2, \ldots, n_{0}+n_{t}, \quad t=1,2,
$$

where $X_{i}^{t}$ is a vector of control variables and $\eta_{i}^{t}$ is the model error term. The parameter $\gamma_{1}^{t}$ is the (conditional) average treatment effect on the treated after controlling for $X_{i}^{t}$. We will estimate alternative specifications of equation (2) by gradually adding control variables to the model. Potential control variables are listed in Appendix B.

We will use a linear regression model to estimate equations (1) and (2). Nonlinearities will be taken into account by the use of nonlinear functions, such as logarithms and quadratic functions. We will also study the role of interaction terms between model regressors. Moreover, we will examine the consequences of using nonlinear regression models in cases where the dependent variable is not continuous. A duration analysis will be performed if necessary.

The models that will be used to estimate the effects of the flyer trial will be similar to the models specified by equations (1) and (2). In the case of the flyer trial, there will be only one treatment group.

Finally, we will estimate heterogeneous treatment effects for both trials using baseline characteristics (see Appendix B) and other control variables (a preliminary list of potential control variables is provided in Appendix $\mathrm{C}$ ). 


\section{Hypotheses}

We are mainly interested in testing the statistical significance of the estimated coefficients $\widehat{\beta}_{1}^{t}$ and $\widehat{\gamma}_{1}^{t}$ of the model parameters $\beta_{1}^{t}$ and $\gamma_{1}^{t}(t=1,2$ for the SMS trial and $t=1$ for the flyer trial). Because we do not know the sign of the estimated coefficients, we will use the following null hypotheses $\left(H_{0}\right)$ and corresponding alternative hypotheses $\left(H_{1}\right)$ to perform one-sided and two-sided $t$-Tests at conventional levels of significance $(1 \%, 5 \%$ and 10\%):

1. $H_{0}: \beta_{1}^{t}=0, H_{1}: \beta_{1}^{t} \neq 0$

2. $H_{0}: \beta_{1}^{t}=0, H_{1}: \beta_{1}^{t}>0$

3. $H_{0}: \beta_{1}^{t}=0, H_{1}: \beta_{1}^{t}<0$

4. $H_{0}: \gamma_{1}^{t}=0, H_{1}: \gamma_{1}^{t} \neq 0$

5. $H_{0}: \gamma_{1}^{t}=0, H_{1}: \gamma_{1}^{t}>0$

6. $H_{0}: \gamma_{1}^{t}=0, H_{1}: \gamma_{1}^{t}<0$ 


\section{Appendix A: SMS messages and draft flyer}

\section{SMS MESSAGES}

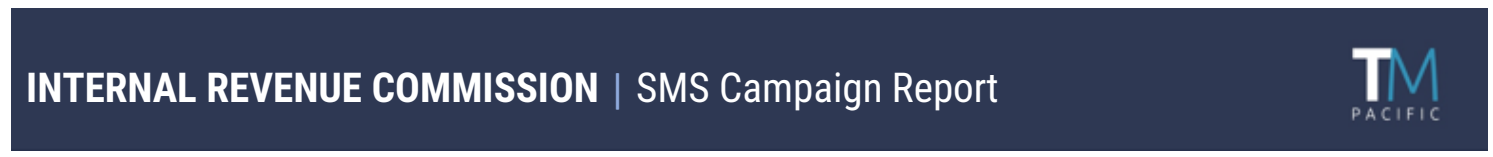

\section{Campaign Objective:}

Specifically tailored messages shipped out in the afternoon to 2 groups of customer owned mobile subscriber base provided by client i.e. (Internal Revenue Commission).
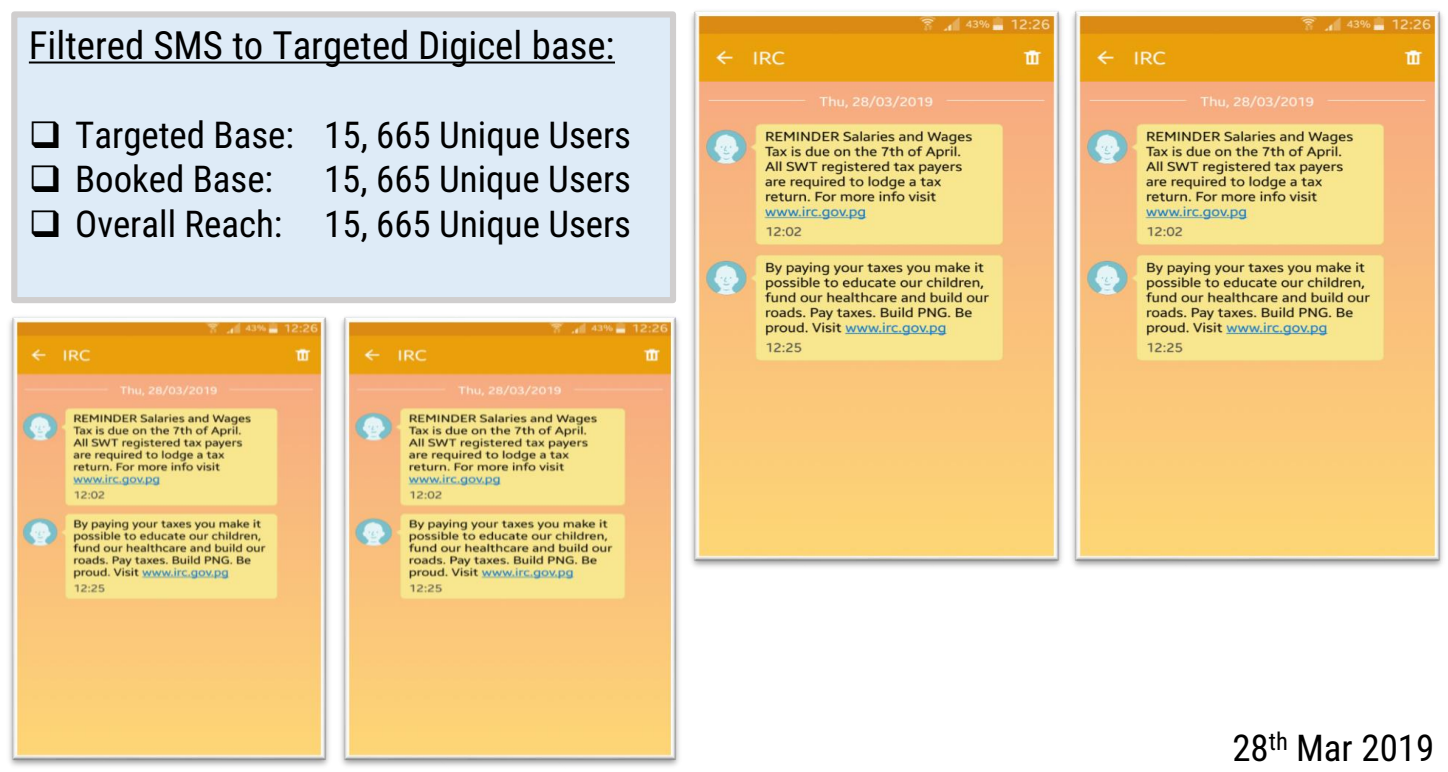


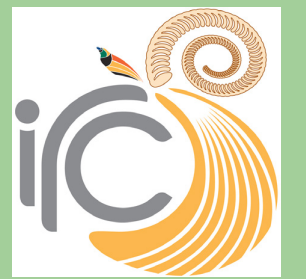

\section{HOW THE TAXES YOU PAY BENEFIT YOU AND YOUR COMMUNITY}

\section{OVER 2 MILLION CHILDREN HAVE ACCESS TO FREE EDUCATION \\ Your taxes are used to build and run schools, just like this one in $\mathrm{X}$. They provide access to primary education for over 2 million children across our country.}

\section{FREE PRIMARY HEALTH CARE FOR ALL CITIZENS}

Your taxes were used to build $Y$ health clinics in 2018. This is ensuring people across PNG have access to more doctors and nurses than ever before.
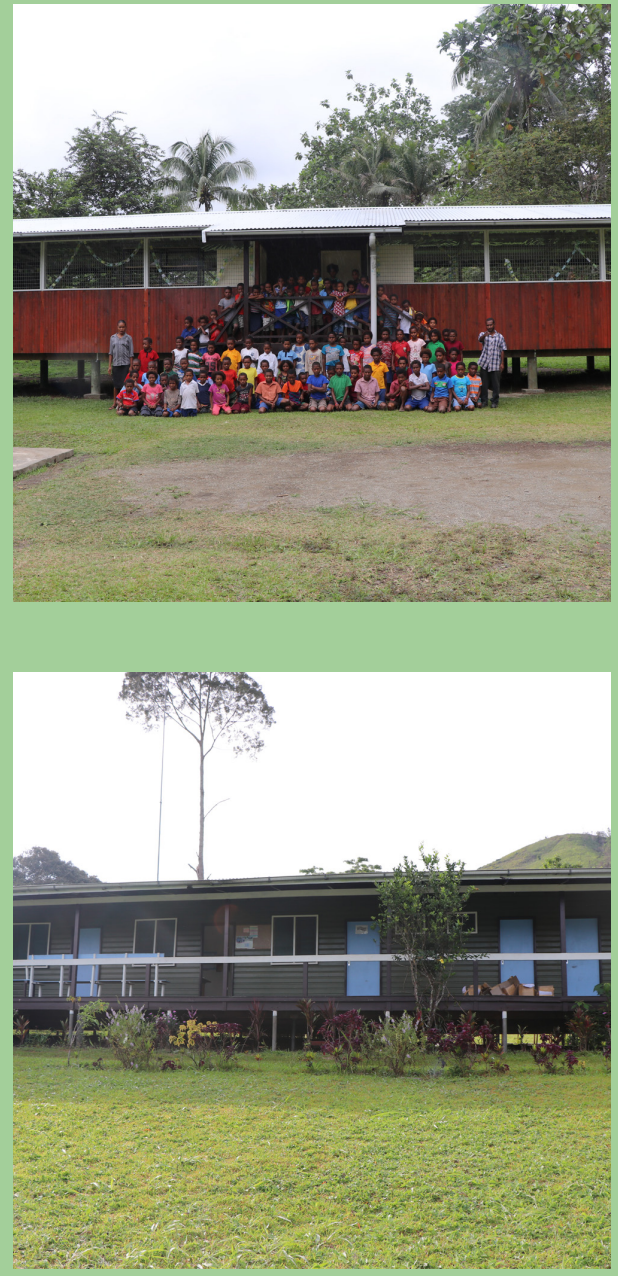

By paying your taxes you make it possible to educate our children, fund our healthcare, and build our roads. Pay taxes. Build PNG. Be proud. Visit www.irc.gov.pg 


\section{Appendix B: Baseline variables used for stratified ran- domization (SMS trial)}

- Province

- Section (similar to industry)

- Segment (Large/Medium/Micro/Small/Unknown/NA)

- Tax Identification Number (TIN) registration year (2013-2019)

- Indicator for nil Goods and Services Tax (GST) lodgment in 2018

- Indicator for nil Salary and Wages Tax (SWT) lodgment in 2018

- Indicator for potential mobile number derived from incomplete numbers 


\section{Appendix C: Potential control variables (preliminary)}

- Tax Period Year

- Tax Period Month

- Date received

- Date entry

- Date assessed

- Form version

- Number of employees on payroll

- Total monthly salary/wages paid

- Number of employees paid SWT

- Total monthly SWT paid

- Total amount SWT deductions

- Sector activity

- Enterprise activity code

- Enterprise activity 